\title{
Successful surgical repair of congenital total cleft sternum with partial ectopia cordis
}

\author{
A Y D IN AYTAÇ and ARGUN SAYLAM \\ Department of Paediatric Thoracic and Cardiovascular Surgery, \\ Hacettepe University Hospitals, Ankara, Turkey
}

\begin{abstract}
Aytaç, A. and Saylam, A. (1976). Thorax, 31, 466-469. Successful surgical repair of congenital total cleft sternum with partial ectopia cordis. Total bifid sternum with or without ectopia cordis is a rare congenital anomaly which is treated successfully in a limited number of cases. Several methods of correction have been described using tissue grafts (cartilage, bone), inert artificial prostheses (acrylic plaques, marlex mesh), and techniques to approximate the sternal bands by relaxation of costal cartilages. In our case the method described by Verska was used to approximate the bifid sternal bands. The successful result in our patient proves the efficiency of this technique.
\end{abstract}

Failure of midline fusion of the sternum is a rare congenital anomaly sometimes associated with multiple defects of the thoracic and abdominal walls, diaphragm, pericardium, and heart (Cantrell, Haller, and Ravitch, 1958; Toyama, 1972; Symbas and Ware, 1973). Partial or total ectopia cordis may exist (Daum and Heiss, 1970; Sabiston, 1958). A patient with total sternal cleft associated with partial ectopia cordis is described.

\section{CASE REPORT}

A 6-month-old baby boy was referred to our clinic because of a defect of the anterior chest wall which had been present since birth. A history of recurrent attacks of respiratory tract infection was given.

On physical examination a total bifid sternum with partial ectopia cordis was seen. The baby was retarded in growth, $62 \mathrm{~cm}$ in height and 5.2 $\mathrm{kg}$ in weight. The heart was covered only with skin. A midline skin raphe was present between the lower portion of the defect and the umbilicus. The heart protruded through the defect (Fig. 1) and paradoxical motion of the heart was observed during respiration. The distance between the upper edges of the sternum was $6 \mathrm{~cm}$ during expiration and $4.5 \mathrm{~cm}$ during inspiration. There were no cardiac murmurs and the pulse rate was $135 / \mathrm{min}$. Physical examination of the other systems was non-contributory.

There was no anaemia. The chest film showed clear lung fields and the edges of the sternal bands

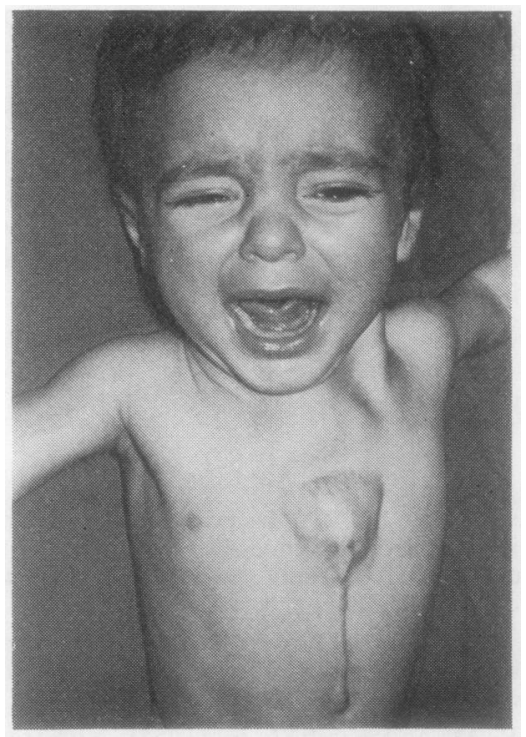

FIG. 1. Preoperative view of the baby while crying. N

(Fig. 2). The electrocardiogram showed slight right ventricular hypertrophy.

At operation a midline vertical skin incision was 0 made from the suprasternal notch to the lowero part of the defect. Skin flaps were prepared bilaterally to a point where the sternocostal junc- $-\frac{1}{8}$ tions were clearly seen. A total cleft sternum waso 


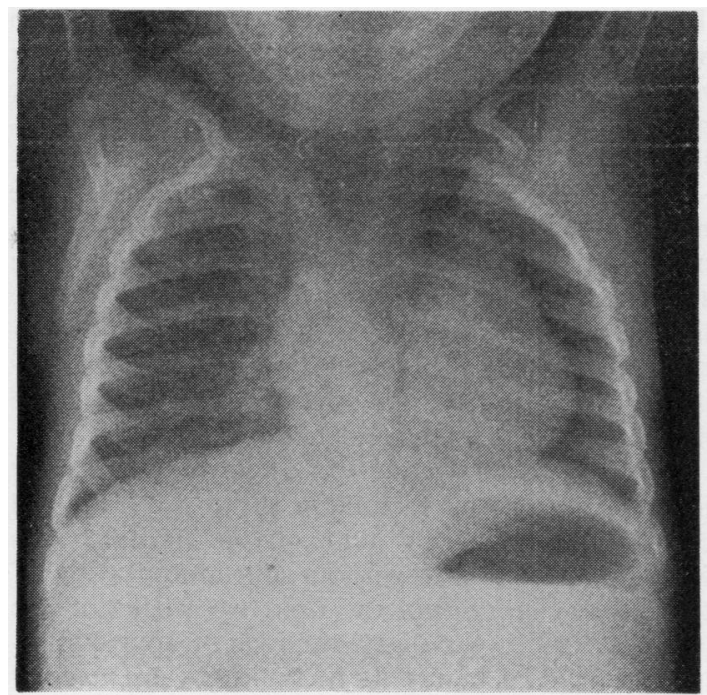

FIG. 2. Preoperative chest radiograph.

confirmed. The pericardium was intact and there was no diaphragmatic defect. The edges of the sternal bands were curetted. The first and third costal cartilages were divided near the midline after transverse incisions had been made in the perichondrium. The second and fourth costal cartilages were divided laterally about $6 \mathrm{~cm}$ from the midline. The sternal bands were temporarily approximated in the midline and a 10-minute waiting period allowed the effect on the heart to be seen. The heart tolerated the procedure well. The sternal edges were then sutured in the midline with nonabsorbable interrupted nylon sutures. The median portion of the second rib and the lateral portion of the first rib were sewn together with absorbable Dexon sutures. Similarly, the median portion of the fourth rib and the lateral portion of the third rib were sutured to each other (Fig. 3). The muscles of the neck above the suprasternal notch were approximated in the midline and sewn together and the skin was closed.

The postoperative course was uneventful and the patient was discharged from hospital on the 10th postoperative day.

\section{DISCUSSION}

Sternal bands form in the sixth week of fetal life and fusion of these separate bands occurs normally in the ninth fetal week from a cranial to a caudal direction (Sabiston, 1958; Larsen and Ibach, 1962; Murray, 1966; Bernhardt, Meyer, and Young, 1968; Verska, 1975). The manubrial ossification centres on each side of the midsternum are fused at the time of birth and fusion of the ossification centres in the sternal body is completed by the sixth year, as stated by Caffey (quoted by Larsen and Ibach (1962) and Murray (1966)).

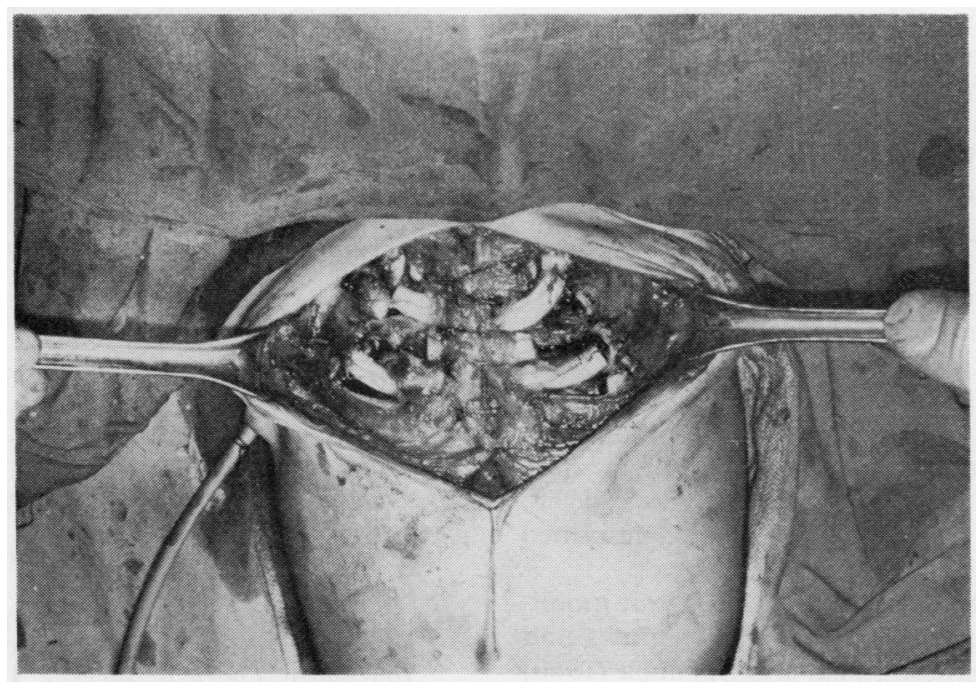

FIG. 3. Completed reconstruction of the chest wall and sternum. Operative view. 
Failure of fusion of the sternal bands results in congenital sternal defects, either complete or incomplete. Cranial sternal V-shaped defects are commonly encountered. Caudal sternal defects are rare, usually associated with omphalocele (Hoffman, 1965). A skin raphe extending upward from the umbilicus is present in the majority of cases (Roccaforte, Mehnert, and Peniche, 1959; Larsen and Ibach, 1962; Murray, 1966; Bernhardt et al., 1968; Daum and Heiss, 1970) and was noted in our patient. This is evidence of an associated abnormality of midline fusion of the upper abdominal skin in these cases (Roccaforte et al., 1959). An infected sinus tract in the distal portion of the cleft may exist in some infants (Verska, 1975).

Although a V-shaped partial sternal defect is frequently observed, total sternal cleft is rare. Partial and total sternal clefts are sometimes compatible with life, and defects in adults, detected during routine hospital admission, have been reported (Larsen and Ibach, 1962; Murray, 1966).

The diagnosis of sternal cleft with or without ectopia cordis is easily made by inspection and palpation. The surgical repair of total bifid sternum in the absence of other skeletal defects has been reported in five patients in the English literature, as cited by Verska, who summarized four cases and added one of his own (Klassen, 1949; Maier and Bortone, 1949; Asp and Sulamaa, 1960; Bernhardt et al., 1968; Verska, 1975).

Surgical correction of these defects is successful in some patients, commonly in those without any associated anomalies. The purpose of the operative methods is the midline approximation of the cleft sternum or closure of the defect by a tissue graft or inert prosthesis without causing pressure on the heart and mediastinal structures. Therefore methods of widening the chest wall have been developed. Sabiston (1958) developed the 'sliding costal cartilage' technique, approximating the sternal bands and widening the chest wall by oblique cutting and separation of the sternocostal cartilages; this technique was later used by Daum and Heiss (1970) in their cases. Direct closure of the bifid sternum by primary suture without any relaxation of the thoracic cage is possible in some infants (Klassen, 1949; Bernhardt et al., 1968; Daum and Heiss, 1970). The technique described by Verska (1975) was used in our case.

Sternal defects have been closed, without mobilization of the chest wall, using tissue grafts and artificial inert prostheses. Asp and Sulamaa (1960) used autogenous skull graft, and Roccaforte $e t$ al. (1959) autogenous costal cartilages. Krontiris and
Tsironis (1964) covered the sternal defect with an $\overrightarrow{\bar{F}}$ acrylic plaque, and Hoffman (1965) used marlex mesh. Hoffman (1965) stated that septic or aseptic necrosis might occur in autogenous and homo-⿳亠丷厂 logous grafts.

Approximation and suture of the muscles of the neck (sternothyroid, sternohyoid and sternocleido-s mastoid muscles) are necessary after repair of the $\vec{O}$ sternal cleft in order to prevent herniation of the lung through a muscular defect. A second opera- $-\vec{\omega}$ tion for herniation of the lung might be necessary if these muscles are not approximated during the first operation (Daum and Heiss, 1970).

The age of the patient is an important factor: in determining the technique to be used. Sternalof cleft can be closed by union of the sternal bands $\circ$ with primary sutures without any mobilization of the costal cage within the first two weeks of life $\vec{\square}$ (Verska, 1975). Auxiliary methods of approximating the sternal bands to the midline are usually necessary in infants more than 1 month old (Verska, 1975). The surgical technique to be used $\vec{\theta}$ must be chosen individually for each patient.

\section{REFERENCES}

Asp, K. and Sulamaa, M. (1960). On rare congenitalo deformities of the thoracic wall. Acta Chirurgica Scandinavica, 118, 392.

Bernhardt, L. C., Meyer, T., and Young, W. P. (1968). Bifid sternum. Case report and surgical management. Journal of Thoracic and Cardiovascular Surgery, 55, 758.

Cantrell, J. R., Haller, J. A., and Ravitch, M. M. (1958). A syndrome of congenital defects involv-产 ing the abdominal wall, sternum, diaphragm,음 pericardium, and heart. Surgery, Gynecology and $\underset{\times}{\stackrel{\Upsilon}{్}}$ Obstetrics, 107, 602 .

Daum, R. and Heiss, W. (1970). Zur operativen Kor rektur angeborener Sternumspalten. Thorax-į chirurgie und vaskuläre Chirurgie, 18, 432.

Heffman, E. (1965). Surgical correction of bifid sternum using marlex mesh. Archives of Surgery, $90,76$.

Klassen, K. (1949). Discussion of Maier, H. C. and Bortone, F. (1949), p. 859.

Krontiris, A. and Tsironis, A. (1964). Bifid sternum. Successful repair by use of an acrylic plaque. 0 Report of a case. Journal of the International College of Surgeons, 41, 301.

Larsen, L. L. and Ibach, H. F. (1962). Complete congenital fissure of the sternum. American Journat of Roentgenology, Radium Therapy, and Nuclear $\Phi$ Medicine, 87, 1062.

Maier, H. C. and Bortone, F. (1949). Complete failure $\square$ of sternal fusion with herniation of pericardium. Journal of Thoracic Surgery, 18, 851.

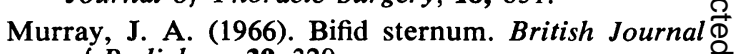
of Radiology, 39, 320. 
Roccaforte, D. S., Mehnert, J. H., and Peniche, A. (1959). Repair of bifid sternum with autogenous cartilage. A case report. Annals of Surgery, 149, 448.

Sabiston, D. C. Jr (1958). The surgical management of congenital bifid sternum with partial ectopia cordis. Journal of Thoracic Surgery, 35, 118.

Symbas, P. N. and Ware, R. E. (1973). A syndrome of defects of the thoracoabdominal wall, diaphragm, pericardium and heart. Journal of Thoracic and Cardiovascular Surgery, 65, 914.

Toyama, W. M. (1972). Combined congenital defects of the anterior abdominal wall, sternum, dia- phragm, pericardium, and heart; a case report and review of the syndrome. Paediatrics, 50, 778.

Verska, J. J. (1975). Surgical repair of total cleft sternum. Journal of Thoracic and Cardiovascular Surgery, 69, 301.

Requests for reprints to: Professor Dr. Aydin Aytaç, Chief, Department of Paediatric Thoracic and Cardiovascular Surgery, Hacettepe University Hospitals, Hacettepe-Ankara, Turkey. 